\title{
THE VARIATIONS IN THE SYSTEM OF THE TRUNKS OF THE POSTERIOR CILIARY ARTERIES* +
}

BY

\section{T. SUDAKEVITCH}

moscow

AN attentive reader will notice the absence in the text-books of ophthalmology of a special section to describe the constant anastomoses of the ophthalmic artery, or, of more importance, the pathological eye-changes connected with them. This fact cannot be explained by the lack of scientific investigation of these anastomoses; they have been well-known for a long time. In 1900, Tichomiroff, Professor of Anatomy, remarked that thanks to Zuckerkandle and Meyer's efforts all the variations of the route and branching of the ophthalmic artery are well known. Also this fact cannot be explained by the insignificant rôle of these anastomoses in the system of the ophthalmic artery and consequently in the life of the eye. Such a supposition is negatived by the anatomical picture itself. It is sufficient to remember that the ophthalmic artery-as was proved a long time ago by prominent anatomists-sometimes starts by two trunks instead of one-the one from art. carot. interna and the other one from art. carot. externa; or only from art. carot. externa. Such a state of affairs is well shown in the illustration of B. Adachi, 1928, A. 1-3.

There is a great difference between a. carot. int. and a. carot. externa; first of all in their architecture and secondly by their relations. That is why the start of the ophthalmic artery only from the art. carot. ext. cannot be compared with its start from the art. carot. interna. This by itself is already sufficient to declare the rôle of the anastomoses to be essential and important for the functions of the eye, and we have to look for a reason why it was so neglected by ophthalmic surgeons.

The reason may be found in the peculiar opinion of the anatomists of the past century $r e$ the orbital vessels; an opinion inherited by ophthalmology. To show more clearly what I mean, I will quote the opinion of Meyer: " although there are wide limits for the ordinary distribution of arterial branches, nevertheless for the more important and larger ones there is a definite law. All authorities ascribe a certain constancy and independence to the central, lacrymal, supra-orbital and 2 ethmoidal arteries. Because of that they received a localisation-sui generis, and they got their

- Translated by N. Pines, London. + Paper read at the meeting of the Ophthalmological Society, Moscow. 


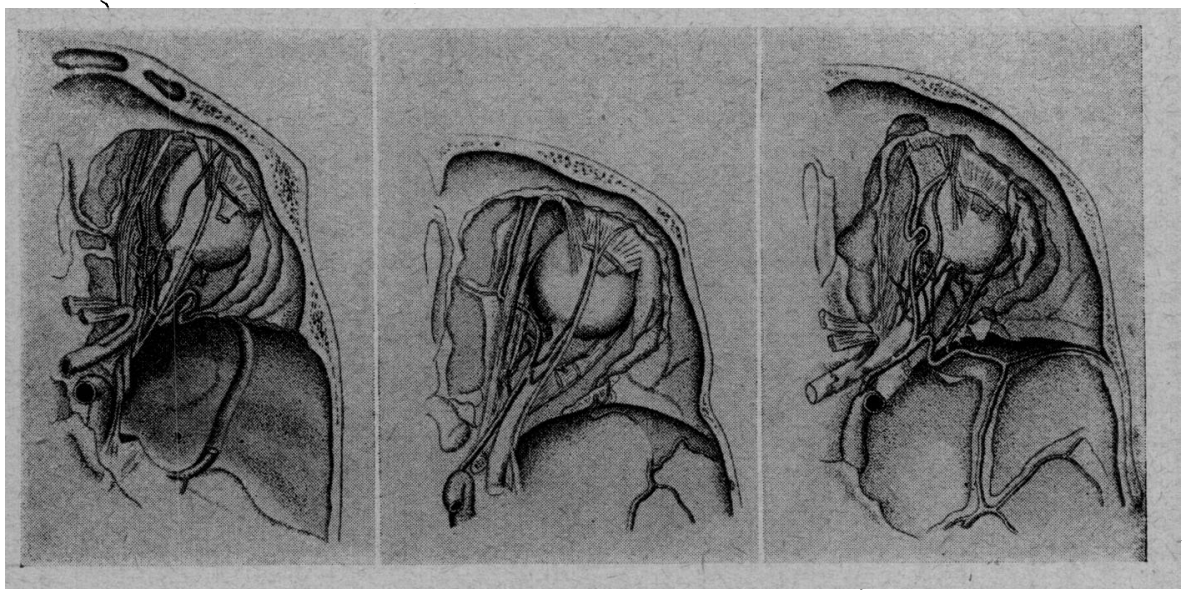

ILLUSTRATION 1.

ILLUSTRATION 2.

ILLUSTRATION 3.

1. A. Ophthal. starts from a. meningea media (male 28 years of age, right side).

2. A. Ophthal. passes under the nervus opticus. A. lacrym. starts from a. menig. med. (male 38 years of age, right side).

3. A. Ophthal. starts by 2 equal trunks from a. carot. int. and art. carot. ext. through a mening media (male 48 years of age, right side).

B. Adachi-" Das Arteriensystem der Japaner '-Kyoto, 1928.

own names. But the muscular and ciliary branches were chiefly considered summarily-jointly to a certain degree" $(\operatorname{Tr}$. Meyer, "Zur Anat. der Orbitalart-Morph. Yahr. Bd. XII, Leipzig, 1887). In those words, as Meyer himself acknowledges, is expressed the general opinion of the anatomists, who reckon as most important only the central art. of the retina, and the ciliary ones only as secondary, described summarily together with the muscular ones. And naturally the question arises, what is then the rôle of the ophthalmic artery in the life of the eye-is it chiefly concentrated in man-especially in man-on the central retinal artery? The physiology of the eye tells us that it is not so. But the authorities who studied the anatomy of the ophthalmic artery and described its system evidently did not follow the principles of physiology. As a result, there is a missing link-the ciliary arteries-and in ophthalmology full use was not made of our previous knowledge of the anastomoses of the ophthal. art. This is why we started to study afresh the system of the ophthalmic artery.

Before describing the results of our own researches we will briefly mention the known forms of variations in the system of ophthalmic artery - the scheme of Prof. Tichomiroff-and adding to it some illustrations (M. A. Tichomiroff, "Variations of the 
arteries and veins of the human body," Kiev, 1900) of Meyer and Quain (Quain's Anatomy, 1866, London).

Tichomiroff's scheme of anastomoses of the ophthalmic art. is as follows :-

(a) From the trunk of the art. carot. interna are branching off twigs, going to the fissura orbital. ophthal. superior and to the trunk of the $n$. opticus; here also are coming the twigs from the trunk of the ophthalm. artery, and they anastomose one with the other, and so form a link between the two arteries. A good illustration is the variant described by Meyer (illustration 4, Fig. $7 b$, r.a.c.).

(b) The ophthalmic artery supplies twigs to the trunk of the n. opticus, that anastomose with one another, the proximal ones going in the distal direction and vice versa. An illustration of this is the same figure 4 ( $7 \mathrm{~b}$, r.a.o.).
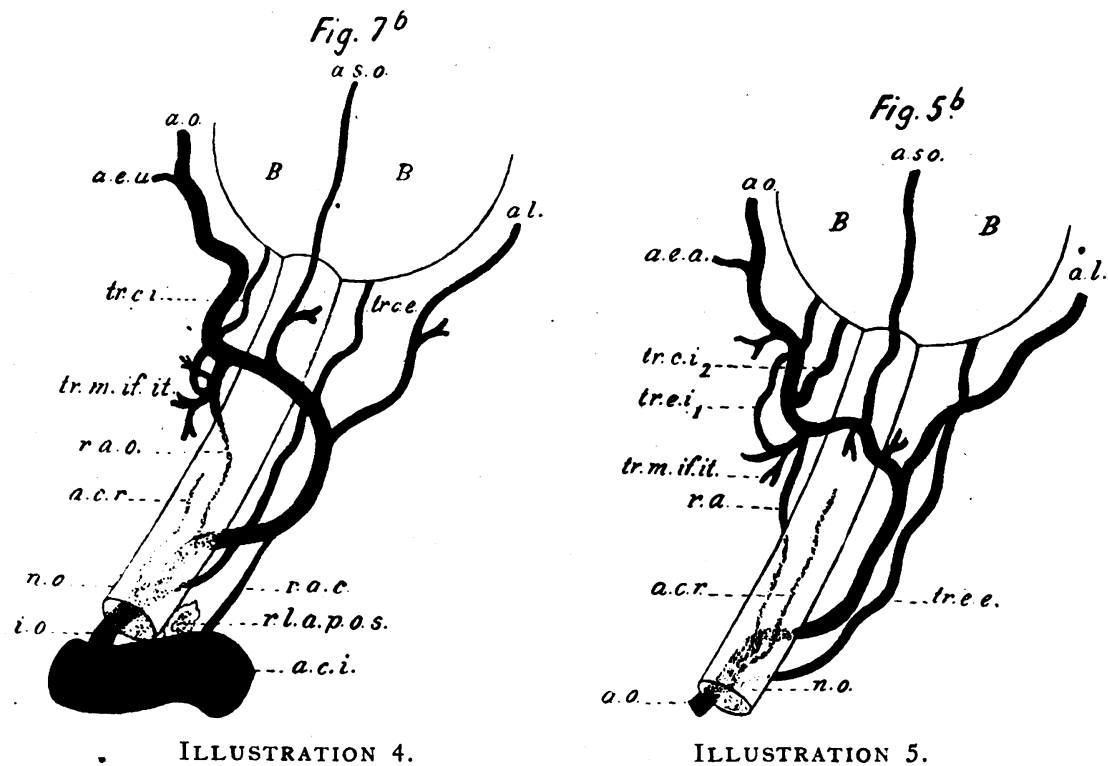

Illus. 4, Fig. 7b (reconstituted normal route)-r. a. c. an anastomotic branch between ar. cen. int. and art. ophthalmica, passing through fiss. orbit. superior, r. a. o.-an anastomotic twig between the branches of the ophthal. art.-it passes under the n. opticus; a. c. i.art. carot. interna; a. o.-art. ophthal. ; tr. c.e. extern. branch of the art. cil. post. long; tr. c. i.-the internal branch of the same artery: a. c. r.-central retinal artery; a. 1.-lacrymal artery; a. s. o.-supraorbit. artery.

Illus. 5, Fig. 5b. (reconstituted normal route)-r. a. anastomotic branch between the branches of the ophthal. art. and it passes under the n. opticus: a. o.-ophthal. art.: tr. c. e.-an external twig of the art. cil. post. long; tr. c. i.-the internal twig of the same art., a. c. r.central retin. artery; a. 1. lacrym. art; a. s. o.-supra-orbit. art. F. Meyer, "Zur Anat. Der Orbitalarterien." 
(c) Twigs from the central ret. art. going to the trunk of the $n$. optic. form an anastomosis with the similar ones from the ar. ciliar. longa posterior. This variant is also described by Meyer (see illustration 5, Fig. $5 b$, r.a.).

(d) Anastomosis with the end of the art. maxillans externa (a. angularis) through the nasal branch (ram. nasalis) of the ar. naso. frontalis (ram' art. ophthalmica).

The same variation is represented in the illustrations of Quain, Testut, Vorobjeff; one of them borrowed from Quain is represented here; illustration $6(\mathrm{IV}, 10)$.

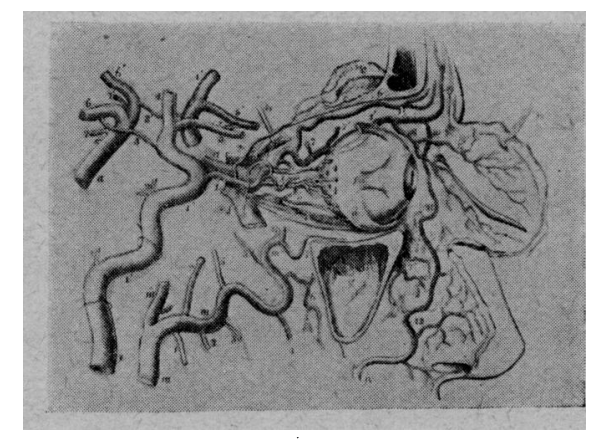

ILLUSTRATION 6.

Illus. 6 (half-schematic $\frac{3}{4}$ ) I-ar. carot. interna : II-art. basil.; IIIthe upper end of ar. carot. ext., III ${ }^{\prime}$. III ${ }^{\prime \prime}$-arteria maxill. interna ; its branches:-1-art. alveol. inferior: 2-ar. mening med; 3, 3-art. masseter. et pterygoidea 4.-ar. buccinat ; 5.,5-art. temp. profund; 6-a. alveol. sup. ; 7-a. infraorb. : 8-the final branch of art. max. inferior ; 9-art. max. ext.; 10-a. angul. ; 12-a nasal. later. 3bi Vessels of the orbit 1, a ophthalmica ; $2-a$. lacrimalis ; $3-a$. centralis retinae : 4, 4-a.a. ciliares posteriores, 5-a musculares, 6-a. supra-orbitalis : 7, 7-a.a. ethmoidales posterior et anterior ; 8, 8', $8^{\prime \prime}$ -a palpebralis; 9-a. frontalis; 10-a. nasal a., which forms an anastomosis with the angular artery (Quain).

(e) An anastomosis of the art. tempor. profund ant. with the lacrymal and muscular branches of the ophthal. artery; this anastomosis is made through the orbital twigs of the temporal artery; they go through the fissura orbital inf: and through the temporal canaliculus (see illustration 6, III, 5; 5), Quain.

$(f)$ Entering the orbit through the fissura orbital super. the branches of the arter. mening. med. form an anastomosis with the twigs of the lacrymal artery. This variation is demonstrated by the illustrations of Meyer and Adachi (see illustration 7, Fig. $3 b$, r.a.m., Meyer, and illustrations 2, Fig. 63, Adachi).

Here it is worth while to speak about 2 other variations that occur with the participation of the ar. mening. media-we spoke 


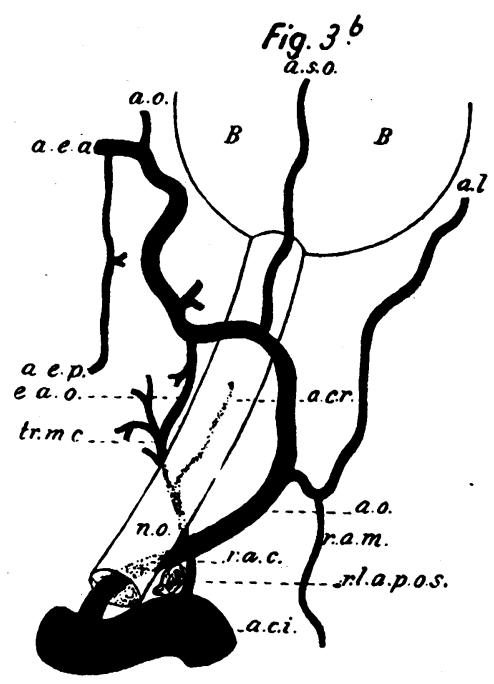

ILLUSTRATION 7 .

Illus. 7, (Fig. 3b) (reconstituted normal route) r.a.m. anastomotic branch between the lacrymal art. and art. mening. media, that passes through the fissura orbit. superior, r.a.o.-anastomotic branch between branches of the ophthalmic artery, r.a.c.-anastomotic branch between the a. carot. int. and ophthalmic artery, that passes through fissure orbitalis superior; a.c.i. carotis int.; a.o.-a. ophthalmica; a.1.-a. lacrimalis; a.s.o.-a. supraorbitalis; a.c.a., a.c.p.-aa. ethmoidales anterior et posterior. -F. Meyer.

about them in the beginning of this paper (see illustrations 1 and 3).

(g) The orbital branches of the ar. infraorbitalis form an anastomosis with the muscular branches of the ophthalmic artery (see illustration 6, III, 7, Quain). F. Meyer, when describing the various positions of the ophthalmic artery, points out the cases where the artery crosses not above, as usual, but below the optic nerve (also Zuckerkandl, Merkel, Adachi, Taguchi, Javle and others). Merkel's “ Macroscopische Anatomie," Graefe-Saemisch, Aufl. I, Bd. 1, T.I. (Cap. 1, 1874), describes vaguely the similarity between the arch of the aorta and some cases of the ophthalmic artery, when its medial part unexpectedly finishes in the posterior ethmoidal artery and so terminates behind the eye instead of going forward, as usual.

When discussing the cause of the above described various positions of the ophthalmic artery, Meyer and others found it in the atrophy or under-development of the main trunk of the opht. art. Meyer even constructed a schematic location of such an atrophy, guided chiefly by variation of the lacrymal and supra- 
orbital arteries; he differentiates three positions of the possible localisation of the atrophic main trunk of the ophthalmic arteryfirst, up to the lacry. art. (Fig. 5a-X ; Meyer, illustration 8); secondly, between the lacrymal and supra-orbital artery (Fig. 7a,

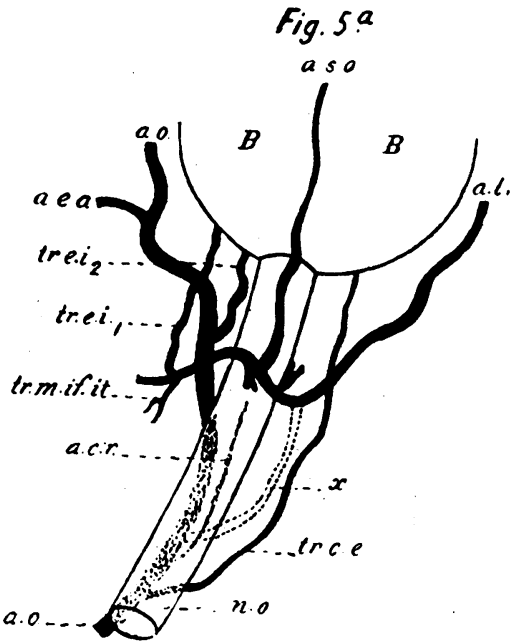

ILLUSTRATION 8.

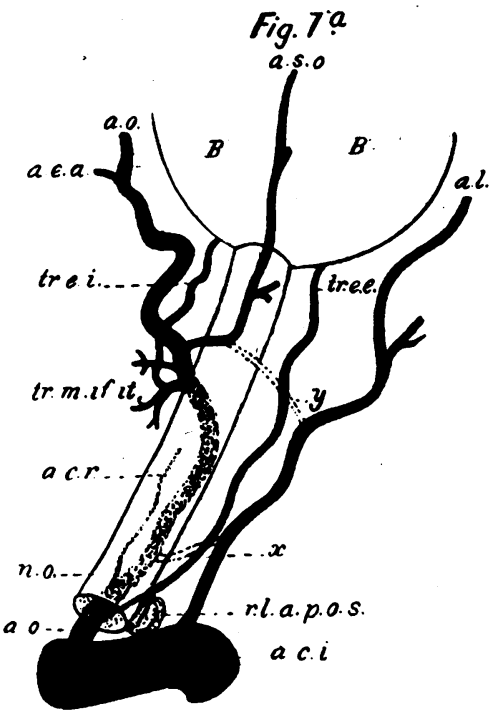

ILLUSTRATION 9.

Illus. 8 (Fig. 5a) Natural state ; $x$-the part of the trunk of the ophth. art. that disappeared; a.o.-a. ophthalmica; tr. c.e.- the external branch of the a. cil. post. long; tr. c.i.-the internal branch of the same art. a.c.r.-a. centralis retinae; a.1.-a. lacrimalis; a.s.o.-a. supraorbitalis.

Illus. 9 (Fig. 7a) Natural state $x$ and $y$-the parts of the trunk of the opht. art. that disappeared a.c.i.-a. carotis interna; a.o. -a. ophthalmica; tr. c.e.-the external branch of ar. cil. post long; tr. c.i.-the internal branch of the same art. a. cil. p.l.; a.c.r.-a. centralis retinae ; a.1.-a. lacrimális; a.s.o.-a. supraorbitalis.

Y ; Meyer, illustration 9); thirdly, more distal from art. sup. orbit. (Fig. 4a, X; Meyer, illustration 10).

He reckons, that at the same time-and in the same case-two such atrophic parts may appear, one before and the other one after lacrym. art. (Fig. 7a, X-Y; illustration 9), and even all three together. (He never saw it himself, but thinks it is possible.)

But Meyer did not explain what is the cause of such an atrophy of the trunk of the ophthal. artery, nor in which period of life does it start; we can only suppose that it happens in the embryonic period, or in the very early post-embryonic period (a very young patient, a female, Meyer). 


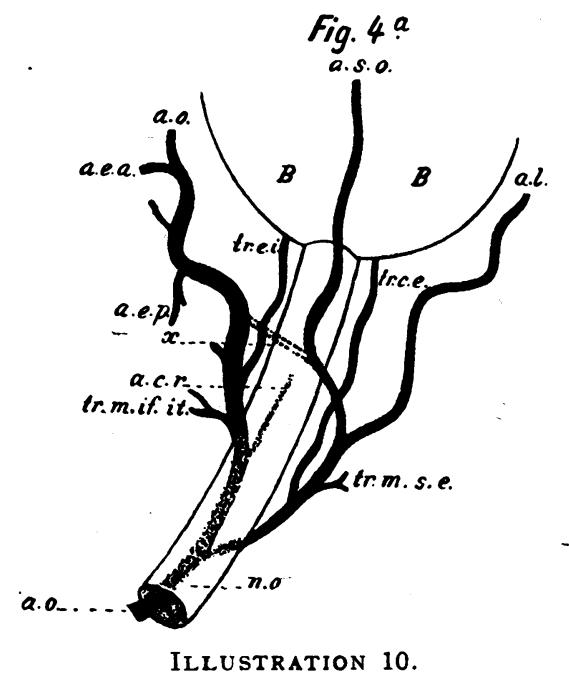

Illus. 10 (Fig. 4a) Natural state ; $x$-the disappeared part of the trunk of the ophthal. art. ; a.o.-a. ophthalmica; tr. c.e.-external branch of the ar. cil. post. long; tr. c.i.-internal branch of the same art, a.c.r.-a. centralis retinae; a.1:-a. lacrimalis; a.s.o.-a. supraorbitalis: tr. m.s.e. - the superior-external muscular branch; tr.m. if. it.-the inferior internal muscular branch.

As far as the connection of the different variations of the branching of the ophthal. artery with this atrophy, Meyer remains the partisan of the old theory and describes the variations of the lacrymal and sup. orbital arteries. The ciliary arteries and even the central retinal artery are left here on the second plane, and are brought forward only when discussing the question of the first branch of the ophthalmic artery.

And so all the researches of Meyer-very valuable indeed-show some detachment of anatomy from physiology and without answering the question (I will speak about that further on), make all the anatomical progress in this direction fruitless. So it happened with Meyer-so is the position to-day.

After all the previous remarks, we will give a short description of our own anatomical studies, with special attention to the two most essential points-the system of the ophthal. artery in the orbit itself and its part within the skull. The ophthalmic artery forms an angle when it goes round the optic nerve before it enters the foramen opticum; first below it and externally, then to the superior external margin and then it turns towards the medial side and crosses the optic nerve from above. 
This angle exists nearly always. As a rarity it may be absent, for instance, if the ophthalmic artery is situated below and to the medial side of the optic nerve. The angle is not always the same, not only in different persons, but even in the same person. In childhood and adolescence the angle is always a sharp one. After 24 years of age, it is chiefly perpendicular, and after 40 years it is an obtuse one. The sharp angle may be preserved, in single

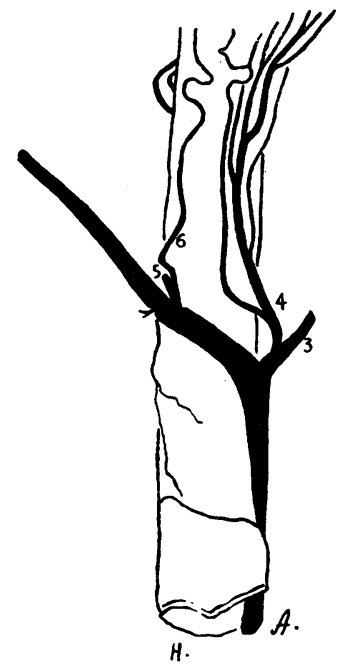

ILLUSTRATION 11.

Illus. 11 (magnified) right eye view from above optic nerve. A-ophthalmic artery: 3-a lacrymal artery, branching off on the site of formation of the first angle of the ophthal. artery, 4-lateral branch of the art. cil. post. long : 5-the superior external muscular branch and a twig ; 6-ar. cil. p. brevis (Male, $4 \frac{1}{2}$ years old).

instances, up to senility, but we do not see it any more after 65 years of age.

We think that nobody up till now has described this angle, but the variations of this angle that are due to age change the correlation between different parts of the ophthalmic artery and so the direction of the pulse-wave, because the artery in this particular spot is always firmly fixed to the membranes of the optic nerve and cannot straighten its angle every time in connection with the pulsewave. It is because of this that the angle changes with age from a sharp to an obtuse one.

This is the result of two constant but opposed factors-one force working in the distal, the other in the proximal direction. If we imagine that these two forces are acting along the axis of the artery, then the vessel will gradually become longer, forming 
bends, and these bends will be evident at every arrival of the pulsewave; Hyrtle already pointed it out-J. Hyrtle, "Handbuch der Anat. der Menschen," 1879. (This locomotive pulse is a physiological phenomenon of the central ret. artery, described by the Translator and others-Translator's remarks.) As an instance, we can point to our fixed preparations and illustrations of the trunks of the posterior long ciliary arteries (illustration 13 and others); we were able to fix the bends of these arteries by injecting them with ether-cellaodine (red praecip. mercury). But if we find as a primary phenomenon an angle of the ophthalmic artery and, moreover, if it is situated in a most fixed part of the vessel, then we can explain it only by a lateral action of a force usually directed from forward backwards. This force may come only from the branches of the ophthal. artery, situated distal to the described angle. These could hardly be the muscular twigs, because they are usually of equal force and are directed in mutually opposed direction. Therefore they could be only the sup. orb. art. and the posterior ciliary arteries, and probably chiefly the medial branch of the latter. To clear these points, I will cite instances. But before that we have to notice the following: the posterior long ciliary arteries and the central retinal artery usually arise together in the first part of the ophthalmic artery. The first to arise is the medial branch, forming a common trunk with central retinal artery; the

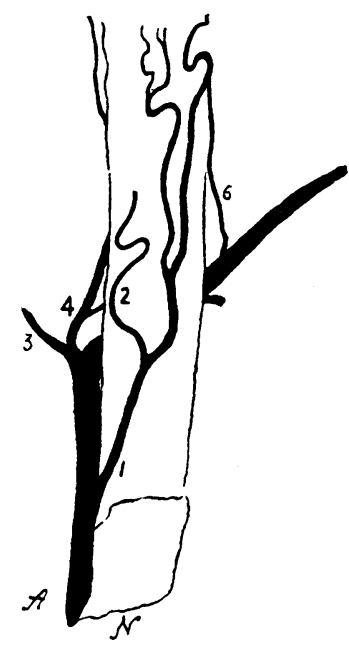

ILLUSTRATION 12.

Illus. 12. The same right eye as in the illus. 11. View from below: 1 medial branch of the art. cil. post. long.; for ming a common trunk with (2) central ret. art. 3-a ; art. lacrymal ; 4-(lateral branch of the ar. cil post. longa.). 
second is the lateral branch and in the angle itself is the third branch, the lacrymal artery (see illustration 12). Consequently the long post. ciliary arteries and the central retinal artery receive their blood supply by the shortest way, nearly a direct line. It is really rare to see, in variation, a different way of branching, and in these cases the medial branch is located in the second part of the

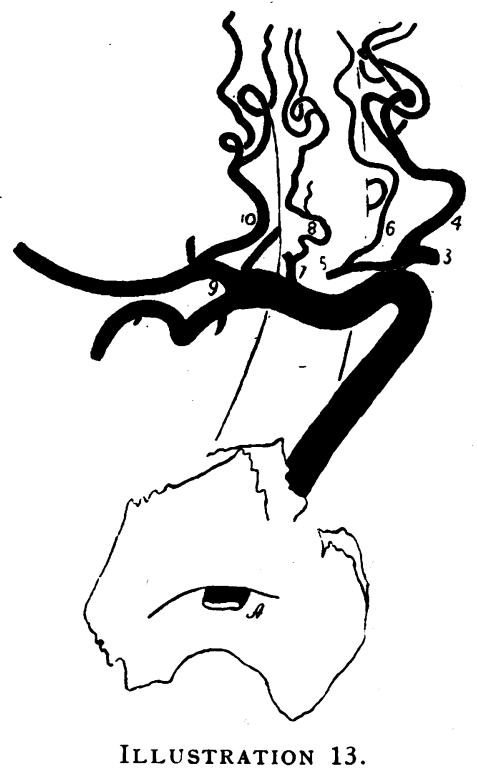

Illus. 13 (magnified) right eye. View from above A-ophthalm. art. ; its proximal part is located in the bony canal that is preserved here, forming an obtuse angle. All the ciliary arteries (except the central ret. artery which branches off in the lateral (first) part of the ophthalmic artery-it is covered from above by the optic nerve)-branch off in the second part of the ophthal. art. (distal to the first angle). 3-lacrym. art. ; 4-lateral branch of the art. cil. post. long; 5-muscular branch with branching off it; 6 a. cil. post. brevis; 7-a muscular branch, arising from it ; 8 ar. cil. p. brevis; 9 -the point of division of the trunk of the ophthal. art., which forms iwo lateral branches, going to the meaial wall of the orbit-the posterior one going by the usual route of the art. ethmoid. posterior; 10 -medial branch of the ar. cil. post. lon. (Male, 65 years of age).

ophthal. artery, and sometimes it is followed there by the central retinal artery. In these cases we can watch the lateral action of the force, as shown by an earlier and more pronounced increase of the angle, gradually changing from a sharp to a perpendicular one, and from a perpendicular into an obtuse one (see illustration 13). Here the medial branch and the rest of the ciliary artery do not receive their blood supply by the shortest way-nearly a direct 
line. The blood-wave first goes sharply round, sometimes even with a reverse direction of the flow of blood, and only after that it reaches the medial branch. As a result, the correlation of forces is upset, the trunk of the ophthal. art. is inclined more and more towards the side of the weaker force, and by so doing increases the angle of deflection of the pulse-wave. And so is built the picture illustrated by us. The picture of the obtuse-angle bend of the ophthalmic artery in the extreme degree, as seen in illustration 13 was not seen by us in ordinary circumstances, even in cases of advanced senility (see illustration 12).

This underlines how important is a definite order of branching of the post. long. cil. arteries for sustaining a favourable correlation in the system of the ophthal. artery from the haemodynamic point of view.

In cases of interruption in the trunk of the ophthal. art. (X) before the point of branching of the lacrym. art. (a. 1) -and that can be seen even in illustrations of Meyer (illustrations 7-9), the medial branch of the long. post. cil. art. (tr. c.i.) is not seen between the first branches-in one case it is not shown (Fig. 4a) and in two other cases (Figs. 5a and 7a) it is shown arising from the medial part of the ophthal. art.

Our researches in 14 cases out of 103 did show that in those 14 cases the ophthal. art. crossed below the opt. nerve; in embryonic or early post-embryonic stage there ought to be a defect up to the first angle of the ophthal. artery, but, as a rule, we saw a variation in the usual order of branching, and the medial branch of the long post. cil. art. was found in the second part, after the lacrymal artery (see illustration 24). Therefore we are entitled to two conclusions.

The first being that we can judge about the interruptions (defects) of the ophthal. artery not only according to variations in the origin of the main trunk of the lacrymal and sup. orb arteries (pointed out already by Meyer), but also on the basis of variations in the rise of the long post. cil. arteries and of the central retinal artery (see our cases, illustration 24), if those defects happened in the part between the foramen opticum and first angle (i.e., before the branching of the lacrym. artery), i.e., where those arteries are usually branching off. The second conclusion is that the unusual rise of the long. post. cil. art. and of the central ret. artery with their appearance on the 2nd part, distal to the first angle, is an unfavourable factor from the haemodynamic point of view. We can easily prove the second conclusion, as nature itself supplies the facts, by providing in those cases anastomoses and accessory branches.

Some time ago Quain affirmed that the posterior ciliary arteries 
do not form anastomoses. If he is right-then it is only in ordinary circumstances. But with variations-it is obvious already from the schemes of Meyer and Tichomiroff-this order is interrupted by nature herself-the posterior ciliary arteries do take part in the anastomoses of the ophthal. artery and form anastomoses themselves as well. Because of these anastomoses a circuitous canal is

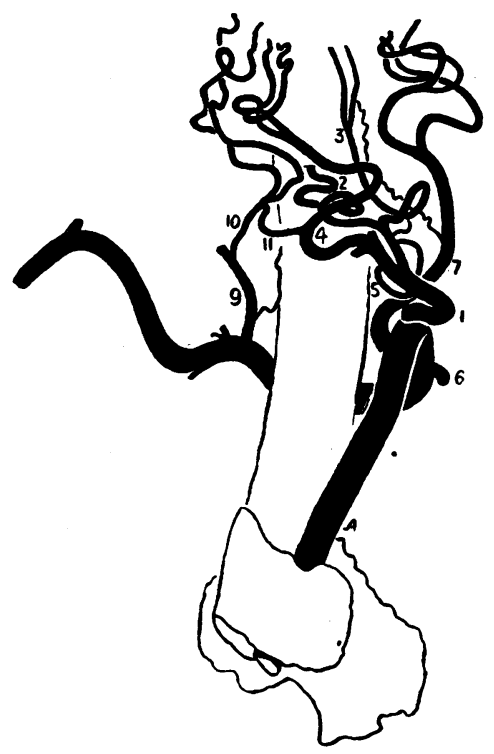

ILLUSTRATION 14.

Illus. 14. Magnified, left eye. View from below. A-ophthal. art, with its proximal part concealed in the bony tunnel preserved here; it forms an obtuse angle, similar to Illus. I3. All the ciliary arteries and the central retinal artery arise from the second part of the ophthal. artery (-distal to the first angle). 1. A powerful lateral branch that supplies 2 ar. cent. retin. and $(3-5) 3$ post. cil. arteries. $7-a$ lateral branch of ar. cil. post. long : 6 and 9-lateral branches, the last one supplying (10) a. post. long. cil. arteries ; 11-powerful anastomosis between the long. post. ciliar. arteries (between 4 and 10), forming a vascular ring round the optic nerve. The ophthal. art. does not go forward, as usual, but follows the route of the ar. ethm. post. (Male 65 years.)

formed, joining the first and second parts, bypassing the angle; and the blood-wave through this canal finds a new collateral way towards the posterior ciliary and neighbouring arteries. This is the same closed vascular ring round the optic nerve that was described by B. Sokoloff (B. Sokoloff, " Ciliary arteries in man," Perm., 1939), as the starting point of the ciliary arteries and was named by him "circulus arteriosus ciliaris periopticalis." The beginning of such a ring we saw already in the first year of life, 
and in this case, the medial branch of the long post. ciliary arteries was situated in the second part of the ophthalmic artery (see illustration 15, 10-A.H.; 8)-medial branch of the long post. cil. arter.

The second factor that we see with such variations-also a compensatory one-is a considerable increase in the numbet of the short post. cil. arteries; here we see not the usual two, but 3-4 and even 5 branches-and they are located not only in the second, but also in the third part.

Another fact is worth mentioning. The resistance against the blood-wave that we have already described as a force acting

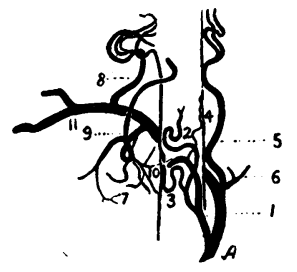

ILLUSTRATION 15.

\begin{abstract}
Illus. 15. Left eye. View from below. A-ophthal. art. whose anterior part. (medial branch of the second part) is divided into two (11) non-equal branches; the posterior-the more powerful one- the real prolongation of the trunk of the oph. art. follows the route of the a. ethmoid. post ; 1 -lateral branch of muscular type supplies a. (2) cent. retinae, and ( 3 and 4 ) short ciliar-arteries; 5 lateral branch of the long. post. cil. art. ; 6-lateral branch of the type of lacrymal artery ; 8medial branch of the long post. cil. art. ; 9-lateral branch of muscular type forms an anastomosis $(\mathrm{X})$ between its branches and another anastomosis (10) joining it with a lateral branch of the first part (I) In such a way a vascular ring is formed, that will supply a collateral route for the first and second part of the ophthal. artery by developing the anastomoses. (A boy of $4 \frac{1}{2}$ months).
\end{abstract}

proximally and at an angle on the trunk of the ophthal. artery, is helped by another force, acting proximally along its route. This happens in cases of the so-called diffused form-of the ophthalmic artery, i.e., when the medial part of its second part looks like being interrupted and forms 2-3 lateral branches that leave the trunk under an angle (illustrations 19 and 20). The force of resistance, starting here $(x)$ works in the reverse direction vis-à-vis to the blood stream, and shows itself in the initial part of the ophthalmic artery, inside the skull. We are now going to analyse it. $(x)$ By its location this part seems to correspond to the third distal cut in the ophthal. art. that was described by Meyer (Fig. 4a, X, illustration 10). We think that with this location of the cut in the ophthal. art. is connected the change of its course from anterior to medialposterior, that was mentioned by Merkel; we saw it in 5 out of 103 cases (illustrations 19 and 20). 
Here in the cavity of the skull, in the narrow space between the entrance of the optic canal and medial to processus clinoideus anterior are meeting together-the internal carotid artery, the first part of the ophthal art., the optic nerve and the edges of the intracranial opening of the optic canal. Their correlation may be varied not only in different personalities, but in the same person at differing ages. I allow myself to visualise this meeting point as a triangular figure with equal sides and the base to the front. Its upper part belongs to the optic nerve, its lower one to the upper part of the bend of the internal carotid, the base-to a surface tangential to the bony edge of the intra-cranial opening of the optic

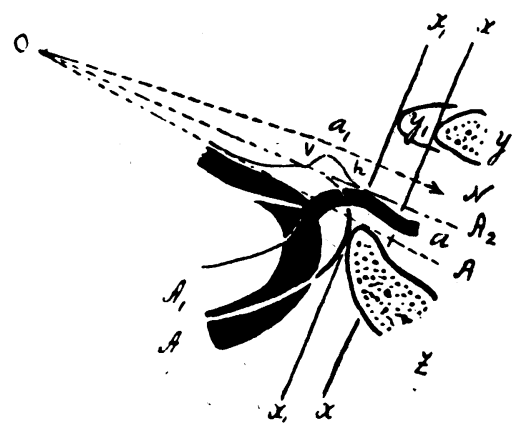

ILLUSTRATION 16.

\begin{abstract}
Illus. 16. A., a-silhouette of the inter. carot. art. and ophthal. artery in a child; $A$, a-the same in grown-up persons; $y, y$-the upper bony edge of the intra-cranial opening of the optic canal; $z$-its lower bony edge; $x, x$-lines of the surfaces tangential to the upper and lower edges of the opening of the canal-the surface tangent to the upper bony edge is the base of the triangle; ON-the upper side, $\mathrm{OA}$ - the lower side of the triangular in childhood, $\mathrm{ON}$ and $\mathrm{OA}_{2}$ in adults; $V$-the short knee and $X$-the long knee of the first part of the ophthal. art. in adults.
\end{abstract}

canal. The ophthalmic artery is located inside of this triangle, between its sides and nearer to the base (see illustration 16).

In the beginning the base of this triangle is relatively large. The point of branching off for the ophthal. art. from the internal carotid and the anterior edge of the arc of carotid, are nearly tangential to the same vertical surface. The angle of the ophthal. art. branching, that is always larger than 90 deg., looks like a crossing of two arcs-ophthal. and inner carot. arteries. This picture we saw in a mature embryo and in children up to 4 years of age. (Illustration 16, A. a.)

In adults the picture is different. The base of the triangle with age becomes smaller. The lower side $\left(\mathrm{OA}_{2}\right)$ gradually disappears, 
i.e., the arc of the inter. carotid is gradually and actively straightening upwards and partly forwards. As a result, the sides of the triangle come nearer, and the space occupied by the first part of the ophthalmic artery is limited. Hence follow all variations in the correlation between the blood-vessels, optic nerve and the supporting tissue. The arc of the internal carotid artery (A) takes the form of an angle. The first part of the ophthal. artery (a) recedes $2-3 \mathrm{~mm}$. backwards from the vertical line tangential to the anterior edge of the arc of the intern. carot. art.

The first part of the ophthal. art. is seen already not as an arc, but as broken-line like $\Gamma$ the shorter knee $V$ the real start of the ophthal. art. $-2 \mathrm{~mm}$. long-nearly preserves the previous relation to the arc of the carot. interna, but this part is perpendicular now to the optic nerve, because the arc itself changed its place; the longer knee-h-passes tangential to the lower edge of the optic nerve.

If we seize the optic nerve with forceps, we can displace it to one side and so approach the initial part of the ophthal. art., or if we press on the arc of the inter. carot. from below, then the optic nerve will be lifted up-we have no obstruction here.

But such a correlation is possible and exists only with a definite structure of the intra-cranial opening of the optic canal, when the edges of both bony prominences are not tangential to one vertical surface (illustration $17, \mathrm{XX} ; \mathrm{X}, \mathrm{X}$ ); just the opposite, the upper one-Y-is moved forwards, the lower one- $Z$-backwards, so that the arc of the inter. carotid is tangential by its edge to the surface of the lower prominence $(\mathrm{Z}, \mathrm{X}, \mathrm{X})$ and does not reach the surface tangent to the upper one $(\mathrm{Y}, \mathrm{XX})$. The ophthal. art. branches off the internal carotid $3.6 \mathrm{~mm}$. backwards from the edge of the upper bony prominence-Y. So we saw it in 9 out of every 10 cases. But in every 10 th case, we saw a different correlation. The edges of both prominences are tangential to the same vertical surface $(Y, Z, X, X)$, so that the arc of the internal carotid is tangential by its anterior edge to the lower prominence and to the surface tangent to the upper prominence. The ophthal. art. branches off the carot. int. under the upper bony prominence $Y$, and the latter forms for it a bony roof.

If in such a case we try to displace with forceps the optic nerve to reach the initial part of the ophthal. art., we will not succeedthe bone that hangs over the artery will be in the way, and also if we press from below on the arc of the internal carotid art.our pressure will be transmitted to the optic nerve, but the latter will not rise over the artery-the same bone will not allow it-as it will be only pressed against the bone. This initial part of the ophthal. art. in such case will be squeezed in the narrow space 
between the sides of the triangle; i.e., between the opt. nerve and the upper knee of the arc of the internal carotid.

And, in our opinion, such a state is important, not only for the function of the ophthal. art., but even for its existence. This shows itself by the changes in the external architecture of the internal carotid and ophthalmic arteries, and by the changes in their lumen.

Let us study it more closely. Ordinarily the difference in the circumference of the carot. ar. before and after the branching off of the ophthal. art. is $2-3 \mathrm{~mm}$., and does not exceed $4 \mathrm{~mm}$., but in our cases, in 5 out of 10 , the difference is 5 and even $8 \mathrm{~mm}$. The increase in this difference is due to the increase in the size of the internal carotid before the branching off of the ophthal. art. Because of that the carot. int. may look like an ampoule (in one of our cases).

The opht. art. on the other hand was smaller inside and was only 4-4.3 $\mathrm{mm}$. Externally the art. had additional bends in the first part-it looked lifeless; and the branches-the posterior ciliary arteries-were abundant in angular bends instead of forming arcs (illustrations 17 and 18).

Finally the lumen of the carot. int. showed here an earlier and more intensive agglomeration of sclerotic spots that formed massive layers and sometimes even a whole tube of bony hardness with a tiny opening for the branching off of the ophthal. art. The lumen of the ophthal. art. is narrow, the usual needle of a 2 gramme syringe could not enter it freely, as usual. And sometimes it went so far, that the initial short knee of the ophthal. art. had only the lumen of a capillary. From 10 of our cases, where the ophthal. ar. branched off the carot. int. under this bony roof, in two we found this capillary lumen of the initial part of the ophthal. art. (illustrations 17 and 18).

We can look upon this capillary lumen of the ophthal. art. as an incomplete intracranial cut. Such an instance has already been described by Meyer for the intra-orbital part. But in our opinion, his cases and the cases (especially the consequences) that we saw not only between adults, but even in infants $3-4$ months old, are really of embryonic origin.

The same intracranial interruptions of the ophthal. art. that we were the first to see ought to be reckoned according to its genesis, not only post-embryonic but even due to the age, because they appear together with senile arteriosclerosis. The immediate cause of their appearance is obvious from the above described architectural changes under a bony roof. The mechanism of these variations is as follows: The initial short knee of the ophthal. art. - $\mathrm{V}$-as described above, is perpendicular to the optic nerve. Because the systolic-wave, knocking at the upper wall of the artery, 
tries to straighten the artery out, but meets the immense obstacle of the bony roof, it loses part of its locomotive energy before it penetrates further into the ophthal. artery. But this lost energy does not disappear without trace-it is transformed qualitatively into a new force-into a pressure, that is transferred back into the arc of the internal carotid, and so increases the intra-arterial pressure of this artery, and this is fairly high in any case. So are created favourable conditions for the local changes, that we have just described.

The capillary lumen, or in other words, an incomplete interruption of the initial part of the ophthal. art., due to age, starves the

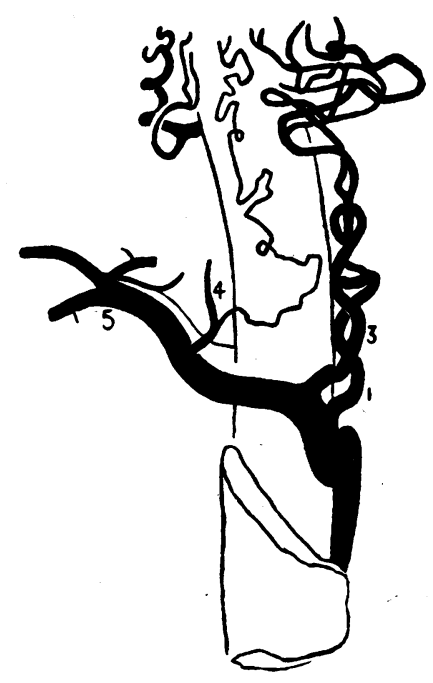

ILLUSTRATION 17.

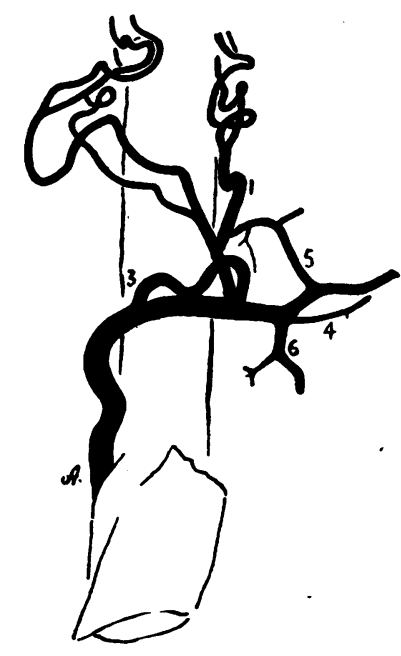

ILLUSTRATION 18.

1llus. 17. Right eye: View from above. The ophthal. art. in its first part has an additional bend; the medial part of the second part (5) is divided into 2 unequal branches, directed towards the medial wall of the orbit, and the more powerful posterior one is really a prolongation of the trunk of the ophthal. art. and follows the route of the post. ethmoid. art. I-a medial branch of the art. cil. post. long. arises, as a first branch by a common trunk with the central retinal art. (covered from above by the optic nerve). 3.- - lateral branch of the ar., cil. post. long ; 4-a lateral branch with a small twig towards the eye.

Illus. 18. Left eye. View from above. The ophthal. art. with an additional bend in its first part, rather weak in its size and appearance: its medial part, in the second part, in spite of its bend, still preserves the magistral type and its forward direction. The order of branching is similar to illus. 17-the first to arise is the medial branch of the art. cil. post. long. by a common trunk with the central ret. artery (covered from above by the optic nerve in such a way that only the dorsal part of the medial twig is seen (I) ; 3-lateral branch of the ar. cil. post. long. In both cases the weakness of the branches, multiplicity of their bends formed with an angle instead of the usual arc, and the increase in their length are remarkable (female, 80 years of age), 
whole system of its chief source of blood supply, and it ought to cause it to perish. But this is an experiment sui generis staged by nature herself, probably not known to Wagenmann when in his experiments he cut across all the posterior ciliary arteries in a rabbit and sometimes produced phthisis bulbi (Martin Bartels"Blutgefasse des Auges bei Glaukom"-Diss, Berlin, 1905). And this experiment of nature looks even more dangerous than the cutting of the ciliary arteries. But we never saw in such cases a phthisis bulbi, in spite of the fact that we are certain that this capillary lumen existed much earlier than our discovery. How then otherwise can one explain it, if not by collateral blood-supply, formed out of permanent anastomoses of the ophthal. art.? And all depends only on the ability of those anastomoses to replace the interrupted route of the blood-supply.

We judge the sufficiency of the development of the ophthal. art. anastomoses as we did before by the development of the variations of the basic magistral ; it would correspond to the law of Krause, mentioned already by Meyer. The law of Krause says, that variations arise because of wrong development of normal anastomoses; and according to this law one would suppose that the anastomoses of the ophthal. art. would be developed better in the case 64 (illustration 17), than in 64a (illustration 18). And the external view of the arteries in both cases follow this lawthey look better in the first case than in the second one, where we see relatively less variations in the basic magistral.

And so on the basis of our cases we are convinced of how important in the life of every human being is the definite osseovascular correlation, which develops in the narrow intra-cranial space in front of the optic canal.

We established the important part of the bony roof as a direct cause of an interruption of the ophthal. artery at certain ages.

But this is not the only cause of such cuts. We saw such an interruption with the normal osseo-vascular relation in this spot in the case of the so-called diffused form of the ophthal. art. described previously; especially when the medial branch of the second part of the ophthal. artery, in the orbit, looks as if being cut, but really divides into three branches, going in opposite directions to each other, and all of them perpendicular to the main trunk. See illustrations 19 and 20 in the case 68a; it appears that such an architecture creates conditions analogous to those, that (or the sequelae of those) we saw in the initial intracranial part of the ophthal. artery, under the bony roof of the intracranial opening of the optic canal. The mechanism of the action, different in form, is essentially the same. Here, in the case of A. 68a, we met an obstacle of bony consistency that narrowed the lumen of 
the initial short knee of the ophthal. art.- $-\mathrm{V}$-in its whole length of $2 \mathrm{~mm}$.

There was only a capillary lumen in the centre of this blockage, hardly visible to the naked eye. This so-called " due to age "incomplete interruption of the ophthal. art. ought to cause the destruction of the whole system. But we did not see it happening.

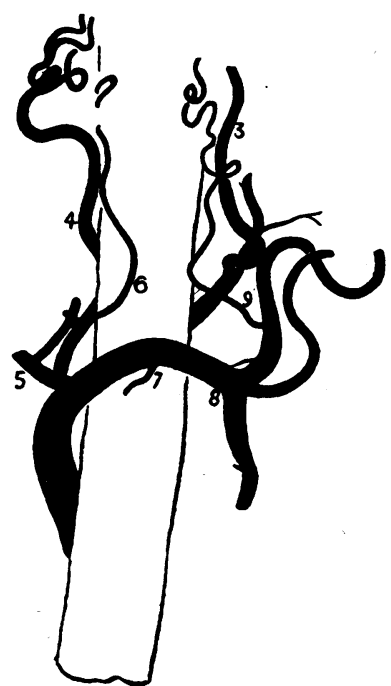

ILLUSTRATION 19.

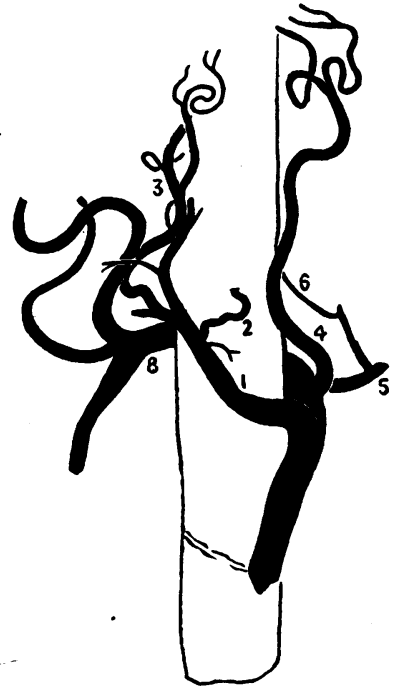

ILLUSTRATION 20 .

Illus. 19 and 20. Left eye. View from above and below. The ophthal, art. goes round the optic nerve by a powerful arc, and medial to the nerve in the second part, suddenly comes to an end (8) and forms 3 lateral branches, that go in different directions with a perpendicular angle. I-powerful muscular branch, from which branch off (2) cent. ret. art., and later a medial twig of the ar. cil. post. long. (3) ; 4-a lateral branch of the a. cil post. long.; 5-a lateral branch of the type of the lacrymal art., that gives off a lateral branch of $2 \mathrm{nd}$ degree with a small twig attached; 6-ar. cil. p. brevis: 7-lateral branch; 8-the point of dividing of the main trunk of the ophthal. art.; 9-a. cil. p. brevis. (Female 45 years of age).

The external architecture of the arteries gives evidence of their good tonus, their good general state. The presence of variations of the ophthal. art., according to Krause's law, points to a good local development of the anastomoses.

If you compare those 3 cases with the "age" interruption of the ophthal. art., then in the latter, we have to acknowledge (68a) - judging by the development of the variations-a better state of anastomoses, than in the other 2 , and in those 2 the second one (64a) has the worst anastomoses.

And so, watching the cases of " age " interruptions in the initial 
intracranial part of the ophthal. art., we realise the important rôle of the anastomoses of the ophthal. art., and we begin to understand their importance.

Let us return now for a moment to the question of the branching of the ophthal. art. and, following in the footsteps of the previous authors, try to contrast an ordinary scheme of this branching -then as a first branch we have to nominate the medial one of the long post. cil., art., forming a common trunk with the central ret.

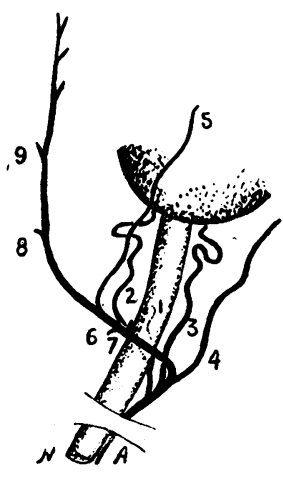

ILLUSTRATION 21.

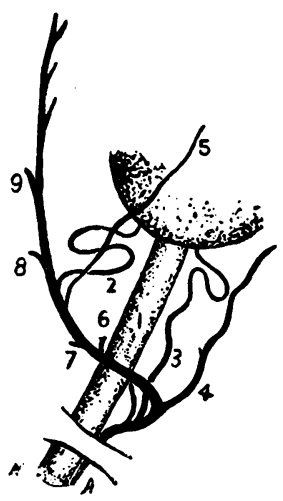

ILLUSTRATION 22.

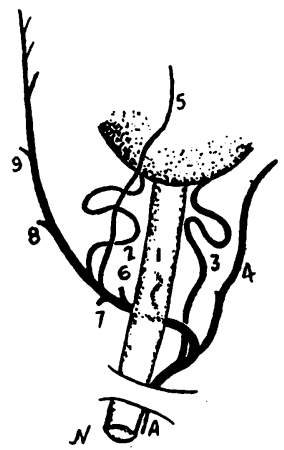

ILLUSTRATION 23.

Illus. 21. Usual type (48.5 per cent.). Art. cil. posteriores and art. centr. retin. branch off together in the first part of the ophthalm. artery. The first to branch off is the medial twig of the art. cil. post. longa by a common trunk with the ar. cent. retin. The central retinal artery has the magistral type with the usual forward direction and crosses the optic nerve from above.

Illus. 22. Variation. The central ret. art. arises first, as the first branch (19.3 per cent.); the long post. cil. art. arise separately, and their medial branch is located in the second part of the ophthal. artery.

Illus. 23. Variation. The lacrym, art. arises first $(13.3$ per cent.) ; all the others - the cent. ret. art., and the long post. cil., ar. branch off it.

art., instead of the central ret. art. according to Meyer, or lacrymal artery according to Testut.

It does not mean, of course, that other branches cannot be the first ones. If we try, guided in each case by the first branch, to divide all our cases in groups, we will have 4 groups. The most numerous one will be the group with the medial one, as the first branch (50 out of 103 or 48.5 per cent.). Then follow 3 weaker groups, nearly equal to one another-2nd with central retinal artery, as the first branch (20 out of $103-19.3$ per cent.); third with a lateral branch (19 out of $103-18.4$ per cent.) and the fourth one-with the lacrymal artery (14 out of 103 or 13.5 per cent). For illustration we include a scheme of 7 illustrations (21-27). 
In the first 4 we see variations of branching (in one of the illustrations showing the lateral branch, as the first, one can also see the usual in such cases variation in the position of the ophthal. art.-going below, and not above the optic nerve-usually in one eye only in all our cases). The remainder of the 3 illustrations show the variations of the position of the ophthal. art. going across the optic nerve medially and from below, interruption of the medial

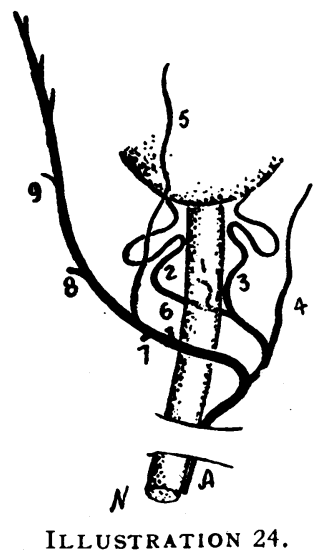

Illus. 24. Variation. The lateral branch of the long post. cil. art. comes off first $\left(18^{\circ} 4\right.$ per cent.) ; the central ret. art.. and the rest of the long post. cil. arteries arise separately and in different parts of the ophthal. art. The ophthal. art. has a magistral type ; goes forward as usual, but crosses the optic nerve from below instead of above $(13.5$ per cent.).

part of the ophthal. art. with an incomplete forward directionand in the last one, a complete change of direction from a forward one to a posterior medial one and the main trunk of the ophthal. art. going the way of the post. ethmoid art.

A scheme of variations in the location and branching of the ophthal. art., according to our researches is shewn in 103 cases, illustrations 21-27, I-YII.

The basic magistral of the ophthal. art. is marked by the letter A; its branches-by numbers, the same as in all illustrations, 1-a cent. ret. art., 2-medial branch of the ar. cil. post. long; 3-lateral branch of the a. cil. post. lon. ; 4--lacrym. art. ; 5-sup. orbit. art. ; 6-7-muscul. art. ; 8-post. ethm. art.; 9-anter. ethmoid art. ; 10the point of division of the basic magistral. Right eye, view from above.

The last variations make the human ophthal. ar. similar to that of the animals, where we always saw the art. end behind the bulb and dividing into two powerful branches-post. cil. art. (see illus. 28 ) - the result in 50 cases of pigs' and cows' eyes. 


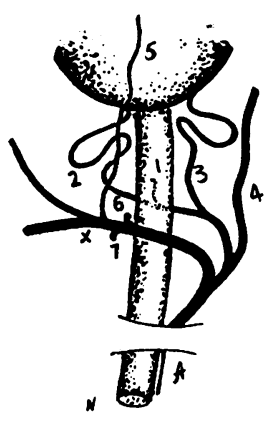

ILLUSTRATION 25

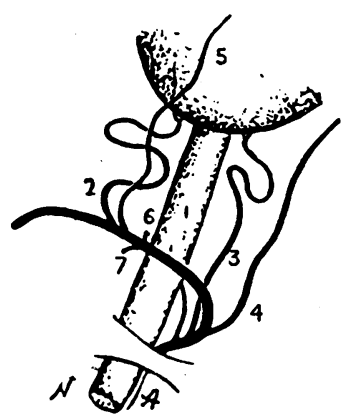

ILLUSTRATION 26.

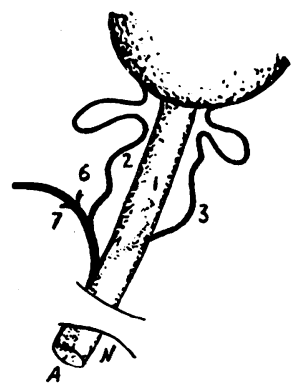

ILLUSTRATION 27.

Illus. 25. Variation. (6.79 per cent.); the ophthal. art. lost the magistral type; the medial part of its second part is divided into $2-3$ lateral branches, out of which the weakest goes forward, as would the magistral, and the more powerful one goes directly to the medial wall of the orbit, following the route of the posterior ethmoid. art.

Illus. 26. Variation ( 4.8 per cent.); the ophthal. art. lost the forward direction, goes to the medial wall of the orbit, follows the route of the posterior ethm. art. (may divide itself or not).

Illus. 27. Variation $(0.97$ per cent.); the ophthal. art. passes under the - optic nerve in the same direction, as illus. 26 .

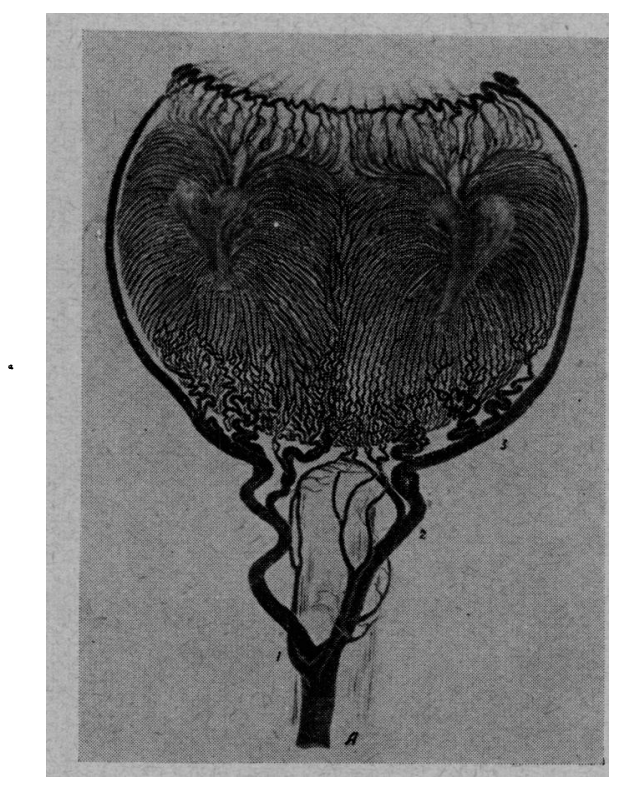

ILLUSTRATION 28.

Illus. 28. Schematic design of the ophthal. art. of the cow and pig. A-ophthal. art.; it gives at first a twig to the optic nerve (I) art. cil. brevis, and later divides in 2 branches-(2) post. long. cil. arteries. and they give twigs to the choroidea-art. cil. post. brevis (3)-in the net of the choroidal vessels two vortices are visible. 
And so, coming back to our question, we have to acknowledge that the first branch most frequently is the medial one of the post. long cil. art. with a common trunk with the centr. ret. art. But it will not be the "norm" that was looked for so unsuccessfully by Meyer, it will be only the usual and more frequent order of branching, purposeful as far as all the long post. cil. art. - arise together in the first part (up to the first angle), and this gives them a great privilege from the haemo-dynamic point of view. But this purposefulness is only relative and may be changed in the reverse position, when the correlation with other tissues (for inst. the supporting one) will be changed, as we saw in our 2 variations with the "age" interruptions of the ophthal. art. (illustrations 17 and 18 , cases 64 and $64 a$ ).

Here, in both cases, the first branch was the medial one of the long post. cil. art. by a common trunk with the cent. ret. art.; it looks like a " norm," but both of them, although in a different degree, proved to be unsatisfactory: with appearance of the interruption due to age, because both of them probably possessed only weak anastomoses. At the same time, the third case of the same group (illustrations 19 and 20, case 68a) had at first quite an extraordinary one-a muscular artery, that even did not enter into our scheme-and it was quite successful in dealing with such an interruption, because in passing through embryonic variations it was provided with good anastomoses and they were brought into action, when needed.

\title{
TRANSPLANTATION OF VITREOUS $*+$ \\ A Preliminary Report
}

BY

\author{
Herbert M. Katzin and John BLum \\ NEW YORK
}

\section{Introduction}

THIS study was stimulated by the recent work that has been done on the transplantation of vitreous particularly by Cutler'. Many attempts have been made in the past to remove vitreous without replacement or to replace it with saline solution, air, or animal vitreous. With the advent of the Eye Bank, and the availability of fresh human vitreous, we determined to conduct further studies. The

* Under the auspices of the Eye-Bank for Sight Restoration, Inc. Director of Research, Herbert M. Katzin. Visiting Research Fellow, John Blum, Adjunct Physician to the University Eye Clinic of Geneva (Switzerland).

† Received for publication, A ugust 13, 1947. 